\title{
Chinese Culture Elements of Public Seat Design
}

\author{
Shanghong Yu \\ Zhengzhou University of Industrial Technology, XinZheng 451100, China \\ 1069561800@qq.com
}

Keywords: public space, public seat, fret, design.

\begin{abstract}
This article is based on aesthetics, sociology, environmental psychology and design psychology theory, study subjects in public space public seats, the survey found that the current public seat design is too common, and some of the artistic taste of the occasion with the public seat does not meet this kind of scene, so we need designers to design works in line with the current environment. In the process of design, we study the extraction of classical elements and the scene, and ultimately determine the use of design elements of the Chinese fret.This design is combined with the practical application, but also shows the artistic and cultural charm of the product.
\end{abstract}

\section{Concepts of public space and public seating}

\subsection{The concept of public space}

The narrow sense refers to the daily life of urban residents, public space for activities and social life .It includes streets, open squares, residential areas, outdoor parks, sports venues, etc. The broad sense mainly refers to the concept that public space is more than just a place, what is more important is that the people who enter the place, as well as the extensive participation, communication and interaction. These activities generally involve the public's spontaneous daily leisure activities, and top-down political rallies.

\subsection{Public seat concept and content}

In today's rapid development of the city Chinese expansion era, the construction of city public space and public facilities design is more and more important, with the design style of the public space is the avant-garde fashion, and combine with Chinese classical elements, the construction of city public space reflects the characteristics and mental state of the city from the side, the city has also become the shortest time to show others their own way.

As the furniture itself, its definition is defined as the use of indoor living appliances ,It is the necessary facilities for building space to produce concrete use value, In the broad sense, furniture is an indispensable tool for people's life, work and social activities. Therefore, it can be argued that the concept of the broad sense of the public seat is used for the crowd of public activities to meet the function of the chair, it is the material basis of the function of public space and the important element in the form of public space.

\section{Design survey and analysis}

\subsection{Market Research and user survey}

In the clear direction of this design, the designer of the use of similar products for the user to observe the evaluation, mainly through the inquiry method, network information collected in two ways to investigate.

According to the market survey, now the public space of public seating design has not paid much attention, some public space such as square, park, public seat city public places is too general or not set public seat. Some places to set up a public seat but also too general, did not show the perfect combination of space, but did not reflect the cultural characteristics of the city, can not give the user a bright feeling.

Seat is an important element in environmental design, it is the main facility of communication space, and it is also the key factor to reflect the whole environment design. The survey found that the 
design style of public seats in the public space is particularly important, if a classical and elegant museum or art gallery placed some modern strong sense of public seating is not harmonious, so we need to fully consider the designer design style of space, and then combined with the theory of knowledge and creativity to design more excellent products.

\subsection{Analysis of the current situation raised questions}

With the pursuit of the art of living, some modern city seat public leisure space other city area ignore stereotyped artistic style, there are some public space collocation ignore the overall design style, such as museums, art galleries, exhibition hall and so on. In addition, some outdoor public seats with great utilitarian purpose, which reflects the city's prosperity, but also highlights the characteristics of the city image, but also can not improve the overall quality of life in the city. So, the designer only has the city style, style and design space heritage closely evoke unique memories and impressions of people for the city culture together to enable people to feel the spirit of the times and the culture of city development in city activities.

\section{Sketch Design and scheme determination}

\subsection{Design ideas}

After the investigation of preparation and the adequacy of existing similar products of the analysis, the design work has entered a stage of conception, make full use of various techniques to design ideas from theory into sketch scheme, which makes the design more intuitive idea.

Innovation 1: to meet the comfort of users of the most basic functions, based on the functions of the appropriate add some auxiliary functions, for example, to improve the taste of art, through the design of extraction of Chinese traditional art elements, and the characteristics of China "FRET" classical furniture simple, thick, refined, elegant design, with clever the characteristics of wood art.

Innovation point 2: shape to be beautiful and generous, jump the appearance of a public seat, you can consider the structure of our traditional furniture design. The law of formal beauty in product modeling: symmetry and balance, contrast and harmony, stability and lightness, proportion and scale, change and unity, rhythm and rhythm.

Innovation 3: the product color collocation to overall color collocation appropriately, avoid abrupt, to give users a sense of warmth, affinity, and collocation related color in the overall tone, works of art to express public seat with China style.

Innovation 4: material application, give full consideration to the cost of the product, select the appropriate product material, such as wood, light and sufficient strength; cushion, cushion with leather breathable material, to prevent the user from long-term use and cause the body skin discomfort.

\subsection{Determine the program}

According to the implementation, functional, reasonable, objective principle, preferably two, compared with the existing products, has diverse functions, innovative style, natural gentle tone, the use of new materials and environmental protection, in line with the concept of people-oriented design, green design, the following is a detailed plan.

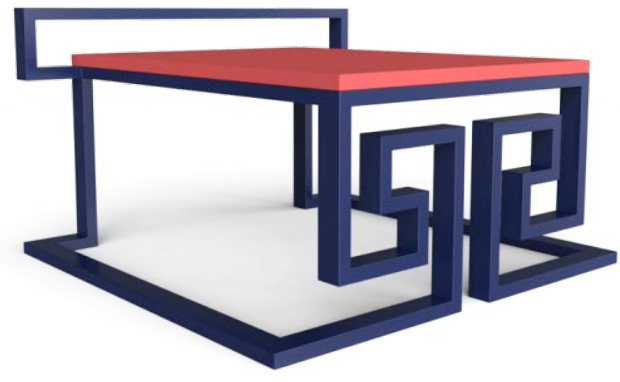

One programme

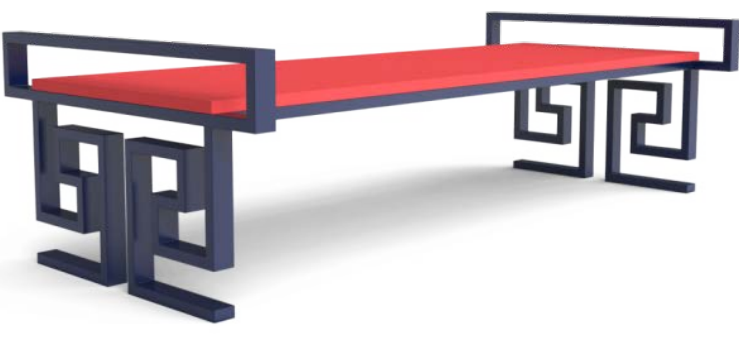

Programme two 
1: the features of structure used in the classical elements "Chinese FRET" and China classical furniture design features, the overall structure is closely linked to a "smart" structure is elegant.

Program features 2: the height of the seat is fully in line with ergonomics, cushion with soft fine leather, and improve grades.

Program features 3: the overall color for red and blue color, looks more elegant. The cushion is made of Chinese red, which is more suitable for Chinese people's aesthetic.

Program features 4: the program is the same as the program for the same series of products, the program for the double seat, or more than 2 seats, the overall color and the program is exactly the same as the 1, still using the red and blue with the.

Program features 5: the series of public seat structures are made with a simple structure with Chinese characteristics. Rietveld said: "the structure should serve the coordination between components in order to ensure the independence and integrity of each component. In this way, the whole can be freely and clearly erected in space, the form can be abstracted from the material."

\subsection{Determine the material}

The material used in the Chinese wind public seat is wood, wood is the traditional Chinese furniture design. Wood has the advantages of light weight, high strength to weight ratio, good elasticity, impact resistance, rich texture and beautiful appearance, easy processing and so on, so the plasticity of the wood is very strong, and it is widely used in the design and production of public chairs.

\subsection{Determine the size}

According to ergonomics, it is possible to determine the size of a public seat that is most ergonomic: the height of the seat surface is the height of the ground to the seat. The appropriate height of the seat should be kept as far as possible to maintain the level of the thigh, as far as possible to maintain the vertical leg, feet flat on the ground, do not stand on tiptoe. If the seat is too high or too low will have an uncomfortable feeling, sitting face should be lower than the front edge of the knee, and made into circular arc. The height of the seat according to the size of the human body in the leg and foot high value, $5 \%$ of women $(342 \mathrm{~mm})$ of men's $(448 \mathrm{~mm})$, desirable between 380 450mm.Leisure chair seat height is generally low. Seat width refers to the size of the hip can meet the required size, so that people can easily adjust the sitting posture.

It is usually necessary to design a large size of ninety-fifth percentile (346mm) of the female body size to meet the needs of the widest body. Generally desirable $400 \sim 500 \mathrm{~mm}$. Placed adjacent to the row of seats, seat width should be slightly larger than the distance between the elbows, so as to avoid crowding. Seat depth. The correct design should be a comprehensive support of the buttocks, the front edge of the seat and the right leg between the appropriate distances, to ensure that the calf can move freely. Usually work chair desirable 350 400mm, rest chair desirable 400 430mm. Is generally not more than $430 \mathrm{~mm}$. According to the ergonomics analysis, we can get a more comfortable state.

\section{Conclusion}

The public seat is mainly used in a number of Chinese style scenes, such as traditional Chinese painting exhibition, or museum, as well as with Chinese classical teahouse, etc. So this chair is designed to integrate cultural values into the value of the product. Through the establishment and development of the design culture, the absorption of knowledge, organization and application can be realized, and the design of cultural products embodies the essence of life. The spirit of culture is embodied in the design, is a feature, is a symbol, is a symbol, is designed to serve the social attributes and cultural attributes of the continuous excavation and exploration of cultural life.

\section{References}

[1] Wang. Ergonomics (Second Edition) [M]. Changsha: Hunan University press, January 2013 Second Edition 
[2] Ji. Ruihai material and craft of product molding [M]. Beijing: Tsinghua University press, Beijing: Beijing Jiaotong University press, 2010

[3] Fang Hai. Modern furniture design in China ([M]). Beijing: China Architecture and Building Press, 2007.1

[4] an. Public facilities and environmental art design [M]. Beijing: China Architecture and Building Press, 2008

[5] Thomas Lockwood. Design thinking: the integration innovation, user experience and brand value [M]. Beijing: electronic industry press, 2012

[6] Adrian Heath. Western Industrial Design In 300 [M]; Changchun, jilin art publishing house, 2003.3 